\title{
ANP AND DEMATEL FOR SIX SIGMA PROJECT SELECTION AND EVALUATION PROCESS IN A COLOMBIAN HOSPITAL
}

\author{
Miguel Angel Ortíz Barrios \\ Universidad de la Costa CUC \\ Barranquilla, Colombia \\ E-mail: $\underline{\text { mortiz1@ @uc.edu.co }}$ \\ Heriberto Alexander Felizzola Jimenez \\ Universidad de la Salle \\ Bogotá, Colombia \\ E-mail: healfelizzola@unisalle.edu.co \\ Santiago Nieto Isaza \\ Universidad de la Costa CUC \\ Barranquilla, Colombia \\ E-mail: snieto2@cuc.edu.co
}

\begin{abstract}
This paper presents an integrated ANP and DEMATEL technique applied to identify and prioritize Six Sigma projects for healthcare companies. identify the most representative Six Sigma projects and their priority. First, the Six Sigma evaluation structure is determined; then DEMATEL (Decision Making Trial and Evaluation Laboratory) is applied to calculate interrelations among healthcare criteria. Finally, the criteria weights are established by ANP (Analytic Network Process). An empirical case for a public hospital is presented, showing the effectiveness of the proposed technique.
\end{abstract}

Keywords: Six Sigma, Evaluation Process, DEMATEL, ANP, Healthcare

\section{INTRODUCTION}

Six Sigma has been widely used for improving production and service processes, through a structured, project-oriented and statistical-based approach, with which it is pretended to analize and intervene the causes that bring about quality, efficiency and productivity problems.

In order to guarantee a successful deployment of a Six Sigma project, there are several critical factors that should be considered; some of these are project selection and prioritization, aligned with organization strategies and customer satisfaction in order to guarantee financial and operational benefits. In this field, the use of multicriteria techniques such as: Analytic Hierarchy Process (AHP), Analytic Network Process (ANP), multiobjective programming models, among others; aid to eliminate the subjective nature in decisión making. Furthermore, objectives and criterion established for decision making can be considered and weighed.

For this reason, an integrated methodology is presented with basis on a previous study done by Büyüközkan \& Öztürkan (2010), which is adapted to healthcare sector criterias, 
with the purpose of providing a decision making support tool for Six Sigma project selection and prioritization in this sector.

\section{LITERATURE REVIEW}

Multicriteria decision methods such as AHP, ANP and DEMATEL; have been rarely applied for Six Sigma project selection and prioritization. Some authors have developed structured methods starting from analytic hierarchy processes. (Banuelas \& Antony, 2003). Bilgen \& Şen (2012) propose an integrated approach between AHP and fuzzy sets to give a solution to a complex process of selecting Six Sigma projects for automotive industry.

Boran, Yazgan \& Goztepe (2011) present a hybrid approach between ANP and fuzzy sets for Six Sigma project prioritizing. In this, starting from a set of projects previously identified, ANP is applied to model decision making process and fuzzy sets to determine and assign the respective weights.

The DEMATEL method is a technique used in the design and analysis of structured models that involve causal relationships between complex factors. In this sense, Büyüközkan \& Öztürkan (2010) develop an integrated approach between ANP y DEMATEL for logistics industry in order to identify critical projects and their prioritization. Its application was based on the use of DEMATEL to construct interrelations between evaluation criteria. Moreover, weighs were obtained from ANP.

\section{HYPOTHESES/OBJECTIVES}

The selection process for Six Sigma projects is one of the most essential aspects in the deployment of this methodology. That is why, this study pretends to validate an effective technique for selecting the most suitable Six Sigma projects for healthcare organizations and consequently aids to achieve the maximum financial benefits and competitive advantage to the applicants. With the design of an evaluation model based on critical quality requirements of healthcare system and then, the identification of the causal relationships among model's subsystems and dependence among healthcare quality criteria from the model, the decision making process will generate satisfactory results at the moment of choosing the best project alternative.

\section{RESEARCH DESIGN/METHODOLOGY}

The selection process consisted of evaluating a project portfolio, and then choosing the deployment of one of the projects, so that organization goals are obtained. For this, organization goals were firstly defined. Starting from this point, project generating factors and subfactors were determined taking into account quality, cost, efficiency and time criterias (See Fig 1). For decision making process, an ANP - DEMATEL evaluation model was implemented, allowing detecting the different interrelations among strategies, factors and subfactors involved in pairwise comparisons that are made to detect dependencies among criteria through DEMATEL. Secondly, the contributions of the distinct criterias are calculated through ANP methodology so that it is posible to select the most effective Six Sigma project with respective to organization goals. In this case, we evaluate a project portfolio with six Six Sigma project alternatives called as A1 
(Improving of patient care opportunity in Obstetric Outpatient), A2 (Improving of patient care opportunity in Internal Medicine), A3 (Improving of User Information System), A4 (Improving of information system opportunity), A5 (Improving of patient care opportunity in Emergency Department) and A6 (Optimization of Drug Inventory System).

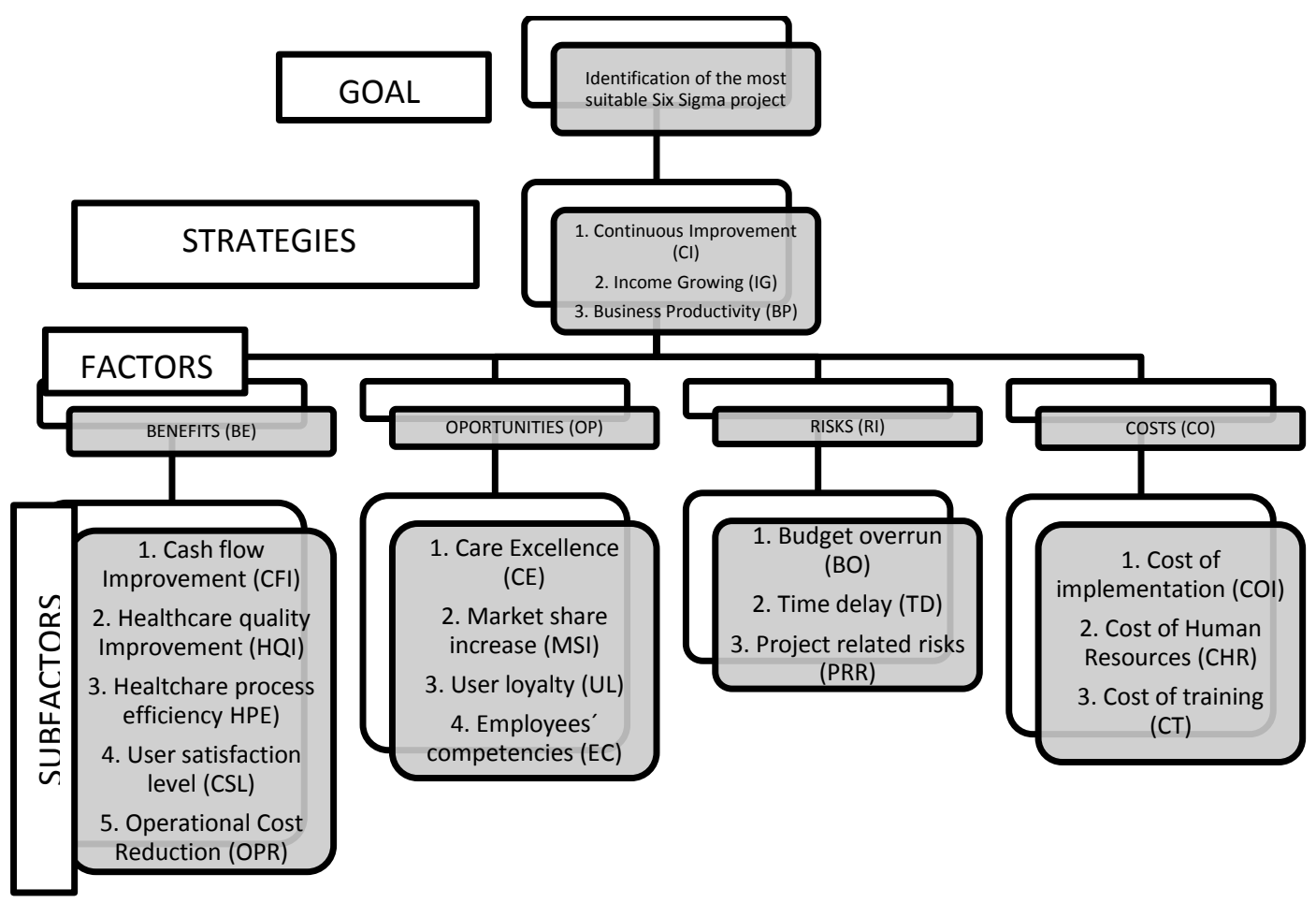

Fig 1. Six Sigma project evaluation model for healthcare

\section{DATA MODEL/ANALYSIS}

After defining the components of the evaluation model, the hospital's Six Sigma team make pairwise comparisons following DEMATEL technique. Firstly, the initial directrelation matrix for strategies is obtained (see Table 1). According to the previous matrix, the normalized direct-relation matrix is calculated (see Table 2). Then, the total-relation matrix is established (see Table 3 ).

Table 1. The initial direct-relation matrix for strategies from healthcare evaluation model

\begin{tabular}{|c|c|c|c|}
\hline & CI & IG & BP \\
\hline CI & 0 & 4 & 3 \\
\hline IG & 3 & 0 & 3 \\
\hline BP & 3 & 4 & 0 \\
\hline
\end{tabular}

Table 2. The normalized direct-relation matrix for strategies from healthcare evaluation model

\begin{tabular}{|c|c|c|c|}
\hline & CI & IG & BP \\
\hline CI & 0 & 0.514 & 0.459 \\
\hline
\end{tabular}




\begin{tabular}{|c|c|c|c|}
\hline IG & 0.378 & 0 & 0.351 \\
\hline BP & 0.432 & 0.486 & 0 \\
\hline
\end{tabular}

Table 3. The total-relation matrix for strategies from healthcare evaluation model

\begin{tabular}{|c|c|c|c|c|c|c|}
\hline & CI & IG & BP & D & D + R & D $-\mathbf{R}$ \\
\hline CI & 2.020 & 2.684 & 2.328 & 7.032 & 13.222 & 0.842 \\
\hline IG & 1.928 & 1.919 & 1.910 & 5.757 & 12.938 & -1.424 \\
\hline BP & 2.242 & 2.578 & 1.934 & 6.754 & 12.926 & 0.582 \\
\hline R & 6.190 & 7.181 & 6.172 & & & \\
\hline
\end{tabular}

Then, the impact diagraph for strategies is done by locating the dataset of $(D+R, D-R)$ as seen in Fig 2. In this case, the threshold value $\alpha$ is calculated as 2.17. According to

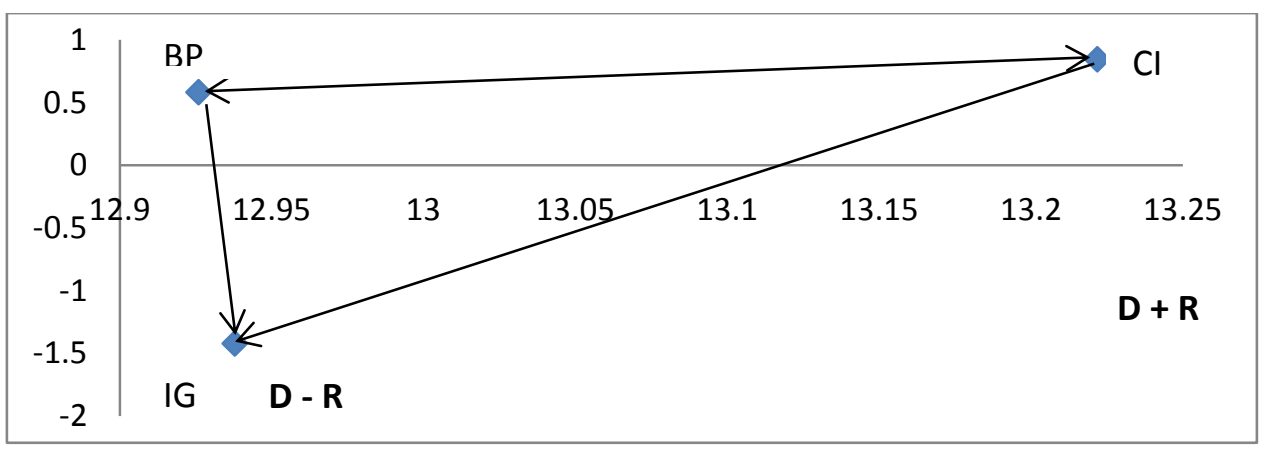

Fig 2. The impact-diagraph-map of total relation for strategies from healthcare evaluation model

$\mathrm{D}$ - $\mathrm{R}$ column in Table 3, it is noticed that CONTINUOUS IMPROVEMENT and BUSINESS PRODUCTIVITY are the dispatchers; on the other hand, INCOME GROWING is the receiver. Looking the impact-diagraph-map over, CONTINUOUS IMPROVEMENT and BUSINESS PRODUCTIVITY have a high impact on INCOME GROWING in Six Sigma strategic phase for this healthcare organization. Finally, the D + $\mathrm{R}$ values for strategy components show a strong inner relationship. The same process is applied for measuring inner dependency between factors and subfactors.

After verifying the inner dependency for each subsystem of the model, ANP is used to estimate the weight of each element. In this step, the hospital's Six Sigma team make comparisons according to ANP's grading scale as shown in Table 4 for pairwise comparisons of strategy with respect to the goal.

Table 4. Pairwise comparison of Six Sigma strategy with respect to the goal from healthcare evaluation model

\begin{tabular}{|c|c|c|c|c|}
\hline GOAL & CI & IG & BP & Weight \\
\hline CI & 1 & 2 & 2 & 0.4761 \\
\hline IG & $1 / 2$ & 1 & 2 & 0.3333 \\
\hline BP & $1 / 2$ & $1 / 2$ & 1 & 0.1904 \\
\hline CR & & & & 0.05 \\
\hline
\end{tabular}

The ANP model shown in this study is solved through Superdecisions software. Previously, CR (Consistency ratio) values are calculated and proved as satisfactory (See 
Table 4). Then, the eigenvalues are entered into the unweighted supermatrix. With the aid of Superdecisions software, the results are obtained, showing Project A1, Improving of patient care opportunity in Obstetric Outpatient, as the most suitable Six Sigma project. The next one in priority is project A2, Improving of patient care opportunity in Internal Medicine.

\section{LIMITATIONS}

During this study, there could be limitations as for the way of combining the qualification scales of DEMATEL and ANP due to they are different. However, it turns out to be a starting point to develop new research. On the other hand, the conclusions derived from this study are specific for the organization in study, but may be replicated in some other healthcare companies with some changes in the actual Six Sigma evaluation model that are relative to its strategic planning.

\section{CONCLUSIONS}

A combined technique for selecting the most suitable Six Sigma project in healthcare companies is proposed with basis on DEMATEL and ANP with a previous design of a specific and robust Six Sigma evaluation model for healthcare sector. This takes into account its different features and can be replicated with little changes in each of its entities with a high level of effectiveness. It helps to optimize the decision making process based on interrelations and criterion weights given a complex Six Sigma evaluation model as shown in this study.

After having done a literature review about healthcare sector, the criteria for the evaluation model was determined and to prove the validity of the proposed technique, an empirical case from a public hospital was used. This technique led the hospital towards an optimal utilization of its financial resources in the improvement of its obstetric outpatient process (Project A1), which represents the best contribution for organizational goal achievement with $11.68 \%$, a low project risk level of $9.9 \%$, a positive impact of $11.63 \%$ on the attainment of benefits and an influence of $14.32 \%$ on factor corresponding to the advantage of opportunities in healthcare sector.

\section{KEY REFERENCES}

Banuelas, R., \& Antony, J. (2003). Going from six sigma to design for six sigma: an exploratory study using analytic hierarchy process. The TQM Magazine, 15(5), 334-344.

Bilgen, B., \& Şen, M. (2012). Project selection through fuzzy analytic hierarchy process and a case study on Six Sigma implementation in an automotive industry. Production Planning \& Control, 23(1), 2-25.

Boran, S., Yazgan, H. R., \& Goztepe, K. (2011). A fuzzy ANP-based approach for prioritising projects: a Six Sigma case study. International Journal of Six Sigma and Competitive Advantage, 6(3), 133-155.

Büyüközkan, G., \& Öztürkan, D. (2010). An integrated analytic approach for Six Sigma project selection. Expert Systems with Applications, 37 (8), 5835 - 5847. 
